\title{
LED Lamp for Application in Medical Centers - Design and Thermal Management
}

\author{
Petko Mashkov, Hristo Beloev, Berkant Gyoch, Tamara Pencheva \\ University of Ruse, Bulgaria
}

\begin{abstract}
The goal of this work is research and development of light sources suitable for use in hospitals, nursing homes, hospices and other similar institutions. During the day spectral power distribution (SPD) of this type luminaire needs to simulate natural day light that affects the natural circadian rhythm of humans. Maintaining the natural circadian rhythm impacts positive on human health, improves mood, prevents the development of depression and helps to overcome them. In the late afternoon increase light in the red-orange part. Light of this kind of spectral composition doesn't inhibit melatonin production and the human body naturally prepares for rest and sleep. At night artificial lighting should be in the red-orange area to enable patients to sleep and staff to fulfill their obligations. Theoretical analysis and selection of suitable LEDs for the realization of the luminaire with the desired characteristics are made. Performed experimental studies make possible achieving the desired characteristics of light and appropriate LEDs' modes of operation.
\end{abstract}

Keywords: Healthy illumination, LED' thermal management, Power LEDs.

\section{INTRODUCTION}

The influence of illumination on the hormonal balance in the human body is well known [1 - 8]. The rapid development of lighting technology based on LEDs allows the light flux of artificial lighting to resemble sunshine. This is particularly relevant in developing lighting systems for hospitals, nursing homes, hospices and others, as lighting of this type maintains the natural circadian rhythm in humans. It positively affects the health and mood of the people and prevents falling into depression.



Fig.1. Circadian rhythm [1]. During the day the blue light suppresses melatonin and increases cortisol levels, so human body is prepared to day job. In the late afternoon, with lack of blue light, hormone levels are shifted and the body is preparing for restful sleep.

In the morning the spectral composition of the light should be more intensive in the blue-violet part of the spectrum (correlated color temperature CCT $=$ $5500 \div 6500 \mathrm{~K}$ ). It is known that the radiation in that part of the spectrum (with maximum close to $440 \mathrm{~nm}-480 \mathrm{~nm})$ stimulates the production of cortisol and improves the cognitive abilities, work productivity, concentration, focus, and has positive effect on the mood - fig. 1. On the other hand light in this part of the spectrum inhibits production of melatonin. In the late afternoon the blue light should decrease and increase light in the red-orange part. Light of this kind of spectral composition doesn't inhibit melatonin production and the human body naturally prepares for rest and sleep.

Night in the hospital must be maintained lighting, which is sufficient for movement of people and to enable staff to perform their duties. In the same time the light should not interfere with restful sleep to patients, i.e. its spectral composition should be in orange - red area.

\section{MATERIALS AND METHODS}

A. Desirable characteristics of light in hospitals, nursing homes, hospices and other similar institutions

The characteristics of human vision are heavily dependent on age - for example the children's eyes are more transparent than those of adults [7]. Therefore light in the blue - violet region (where light quanta are more energy) is harmful to children's eyes and its intensity should be limited in rooms inhabited by children. For such premises maximum color 
temperature of light output should be limited to around $4000-4500 \mathrm{~K}$. In rooms for accommodating elderly maximum color temperature of the luminous flux is normal to reach $6000-6500 \mathrm{~K}$. For rooms in nursing homes color temperature of lighting can be increased above $7500 \mathrm{~K}$ as well as to increase the illumination of the premises - this reflects positively on mood and prevents depression in older people.

The above mentioned features set these requirements to the designed luminaire:

- Depending on the time automatically should be changed the spectral composition of light output, so as to mimic the characteristics of sunshine;

- Depending on the type of the patients the maximum color temperature of the light flux should be limited to three grades - up to about 4000 $4500 \mathrm{~K}$; to about $6000-6500 \mathrm{~K}$ and to about 7500 $8000 \mathrm{~K}$.

- Ranging from 5 p.m. to 7 a.m. color temperature of white light output of the luminaire should be around $3000 \mathrm{~K}$.

- The luminous flux of the lamp can be adjusted over a wide range - for example from $20 \%$ to $100 \%$.

- At night when the patients sleep luminous flux should be in the orange - red spectral region and its intensity can be remotely controlled from 0 to $100 \%$.

B. Choice of LEDs with proper spectral and power characteristics

Using the procedure described in [2] theoretical analysis and selection of appropriate combinations of LEDs and LED modules for lighting fixture with features suitable for the lighting of hospitals, nursing homes, hospices and others are made.

$$
\begin{gathered}
\mathrm{X}=\mathrm{x} *(\mathrm{Y} / \mathrm{y}) ; \mathrm{Y}=\mathrm{Y} ; \mathrm{Z}=(\mathrm{Y} / \mathrm{y}) *(1-\mathrm{X}-\mathrm{y}) \\
\mathrm{Xmix}=\mathrm{X} 1+\mathrm{X} 2+\mathrm{X} 3 ; \mathrm{Ymix}=\mathrm{Y} 1+\mathrm{Y} 2+\mathrm{Y} 3 ; \\
\mathrm{Zmix}=\mathrm{Z} 1+\mathrm{Z} 2+\mathrm{Z} 3 \\
\mathrm{X}_{\text {mix }}=\mathrm{Xmix} /(\mathrm{Xmix}+\mathrm{Ymix}+\mathrm{Zmix}) \\
\mathrm{y}_{\text {mix }}=\mathrm{Ymix} /(\mathrm{X} \operatorname{mix}+\mathrm{Ymix}+\mathrm{Zmix}) \\
\text { Фmix }=\mathrm{Y} 1+\mathrm{Y} 2+\mathrm{Y} 3
\end{gathered}
$$

Where:

$\mathrm{X}, \mathrm{Y}, \mathrm{Z}$; Xmix, Ymix, Zmix are color coordinates; $\mathrm{x}, \mathrm{y}, \mathrm{x}_{\text {mix }}, \mathrm{y}_{\text {mix }}$ are chromaticity coordinates according to 1931 CIE Chromaticity Diagram.

Experimental model of lamp which allows to investigate the possibilities for realization of the desired characteristics of the luminous flux, options for their management and to meet the stated above requirements is made. For the manufacture of the experimental model the following LEDs are used: one warm white CXA 2520 LED module (CCT 3500 $\mathrm{K}$ ), five blue XPE LEDs (Xlamp - CREE Inc.) and eight red XPE LEDs (Xlamp - CREE Inc.).
Lamp's spectral characteristics using $1 \mathrm{~m}$ integrating sphere and UV-VIS Spectrometer from Stellar Net. are obtained experimentally.

Thermal loading of LEDs is tested in a thermal chamber. Solder points' temperatures distributions are obtained experimentally using IR camera ThermaCam E300 - FLIR Systems and verified by conventional measurements by thermocouples.

\section{RESULTS AND DISCUSSION}

A. Thermal management and power consumption Thermal resistance model for evaluation LEDs' temperature load described in [2] is used.

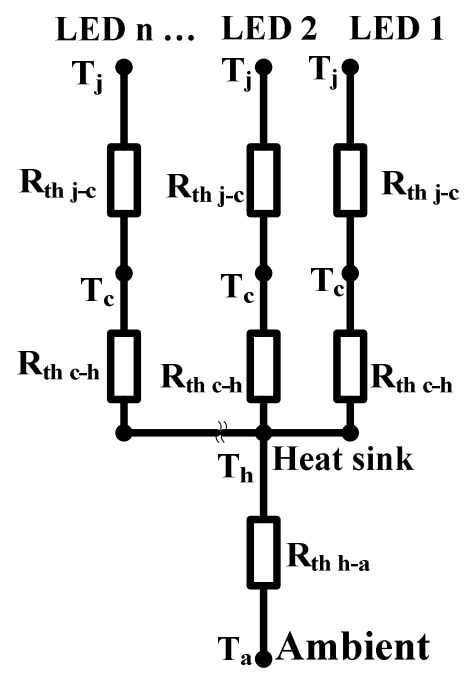

Fig. 2. Thermal resistance model [2]. $\mathrm{R}_{\mathrm{th} \text { j-c }}$ - thermal resistances from junction to case; $R_{\text {thc- }} \mathrm{h}^{-}$thermal resistance from case to heat sink; $R_{\text {th h-a }}$ - thermal resistance from heat sink to ambient; $T_{j}$ and $T_{c}$ are junction and case temperatures correspondingly.

The maximal junction temperature ( $\left.\mathrm{T}_{\mathrm{j} M A x}\right)$ depends on the ambient temperature ( $\left.\mathrm{T}_{\mathrm{a}-\mathrm{max}}\right)$, LEDs' power and all the thermal resistances in the model:

$$
\mathrm{T}_{\mathrm{jMAX}}=\mathrm{T}_{\mathrm{a}-\mathrm{max}}+\left(\mathrm{R}_{\text {thj-c }}+\mathrm{R}_{\text {thc-h }}\right) * \mathrm{P}_{\mathrm{LED}}+\mathrm{R}_{\text {thh-a }} * \mathrm{P}_{\text {tot }}
$$

The forward current $\left(\mathrm{I}_{\mathrm{F}}\right)$ and voltage $\left(\mathrm{U}_{\mathrm{F}}\right)$ of LEDs allow to calculate the consumed electrical power: $\mathrm{P}_{\mathrm{LED}}=\mathrm{I}_{\mathrm{F}} * \mathrm{U}_{\mathrm{F}}$;

The nominal power of CREE CXA 2520 LED module is: $\mathrm{P}_{\mathrm{WHITE}}=\mathrm{I}_{\mathrm{F}} * \mathrm{U}_{\mathrm{F}}=0.55 * 35=19.25 \mathrm{~W}$ and varies from about $10 \mathrm{~W}$ at $\mathrm{I}_{\mathrm{F}}=300 \mathrm{~mA}$ to about $34 \mathrm{~W}$ at $\mathrm{I}_{\mathrm{F}}=800 \mathrm{~mA}$.

The power of blue LEDs varies from about $0.7 \mathrm{~W}$ at $\mathrm{I}_{\mathrm{F}}=200 \mathrm{~mA}$ to about $2.8 \mathrm{~W}$ at $\mathrm{I}_{\mathrm{F}}=800 \mathrm{~mA}$.

Maximal total power (at $\mathrm{I}_{\mathrm{F}}=800 \mathrm{~mA}$ through CXA 2520 LED module and blue LEDs):

$$
\mathrm{P}_{\mathrm{tot}}=\mathrm{P}_{\mathrm{WHITE}}+5 * \mathrm{P}_{\mathrm{BLUE}}=48 \mathrm{~W}
$$

The thermal resistances are as follows: CREE CXA 2520 LED module $-\mathrm{R}_{\text {th } \mathrm{j} \text {-c }}=0.8 \mathrm{~K} / \mathrm{W}$; blue LED $\mathrm{R}_{\text {th j-c }}=9 \mathrm{~K} / \mathrm{W}$ [2]; 
Environment. Technology. Resources, Rezekne, Latvia Proceedings of the $11^{\text {th }}$ International Scientific and Practical Conference. Volume III, 207-212

Using equation (6) heat sink with thermal resistance from heat sink to ambient about $\mathrm{R}_{\mathrm{th} \mathrm{sp}-\mathrm{h}}=$ $0.5 \mathrm{~K} / \mathrm{W}$ is chosen.

\section{B. Spectral characteristics and CCT}

Measured spectral characteristics of CXA 2520 at nominal operating regime (forward current $\mathrm{I}_{\mathrm{CXA}}=550 \mathrm{~mA}$ ) are shown in fig. 3.

The luminous flux' spectrum of the CXA 2520 is typical warm-white with correlated color temperature (CCT) about $3500 \mathrm{~K}$. The relatively small maximum in the blue region $(440-480 \mathrm{~nm})$ does not suppress melatonin synthesis and is good for illumination in the late afternoon or evening.

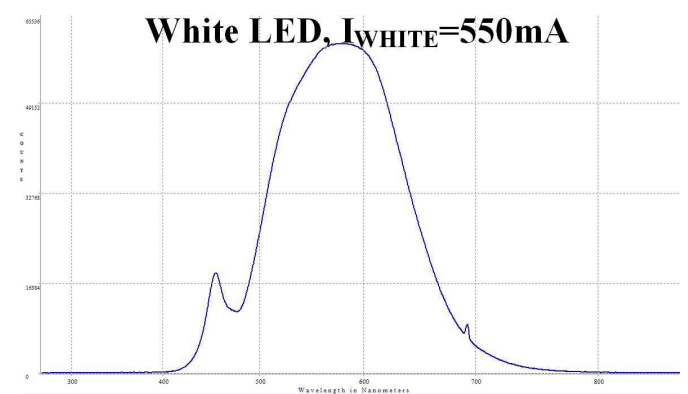

Fig. 3. Relative SPD of CXA 2520 LED module. The current's value is the nominal $\mathrm{I}_{\mathrm{CXA}}=550 \mathrm{~mA}$.

By control of the forward current's value $\mathrm{I}_{\mathrm{CXA}}$ from $300 \mathrm{~mA}$ up to $800 \mathrm{~mA}$ the luminous flux of the LED module can be set to the desired value in the range of 900 to 2400 lumens. Changes in color temperature are negligible i.e. the luminous flux is suitable for lighting evening in hospitals.

When white LED module and blue LEDs are used in combined mode of operation, options for achieving the desired spectral composition and luminous flux are much larger:

- $\mathrm{I}_{\mathrm{CXA}}=300 \mathrm{~mA}$; the current's value through blue LEDs is changed from $\mathrm{I}_{\mathrm{BLUE}}=200 \mathrm{~mA}$ up to $\mathrm{I}_{\mathrm{BLUE}}=500 \mathrm{~mA}$. CCT of the luminous flux changes from about $4000 \mathrm{~K}$ to about $14000 \mathrm{~K}-$ fig. 4 .

The total luminous flux varies from $1000 \mathrm{~lm}$ to $1200 \mathrm{~lm}$

- $I_{C X A}=400 \mathrm{~mA}$; the current's value through blue LEDs is changed from $\mathrm{I}_{\mathrm{BLUE}}=200 \mathrm{~mA}$ up to $\mathrm{I}_{\mathrm{BLUE}}=800 \mathrm{~mA}$. CCT of the luminous flux changes from about $4500 \mathrm{~K}$ to about $13500 \mathrm{~K}-$ fig. 5 .

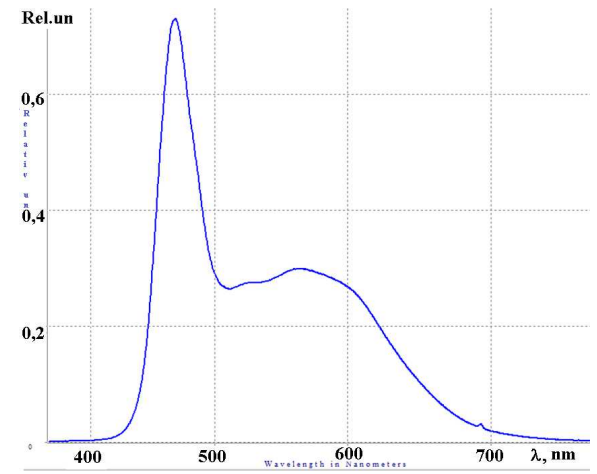

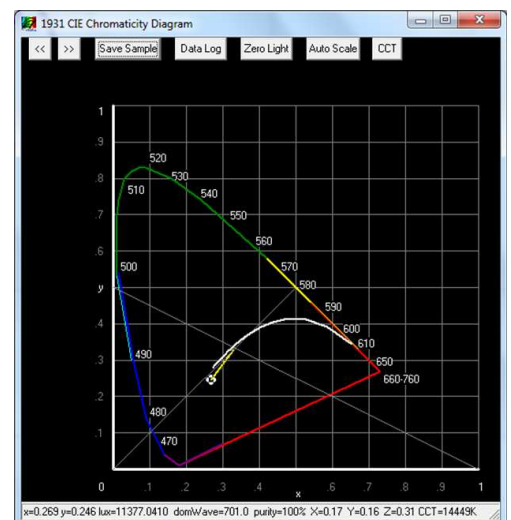

Fig. 4. Relative SPD of the lamp. The current's values: $\mathrm{I}_{\mathrm{CXA}}=300 \mathrm{~mA}, \mathrm{I}_{\mathrm{BLUE}}=500 \mathrm{~mA} . \mathrm{CCT} \approx 14000 \mathrm{~K}$.
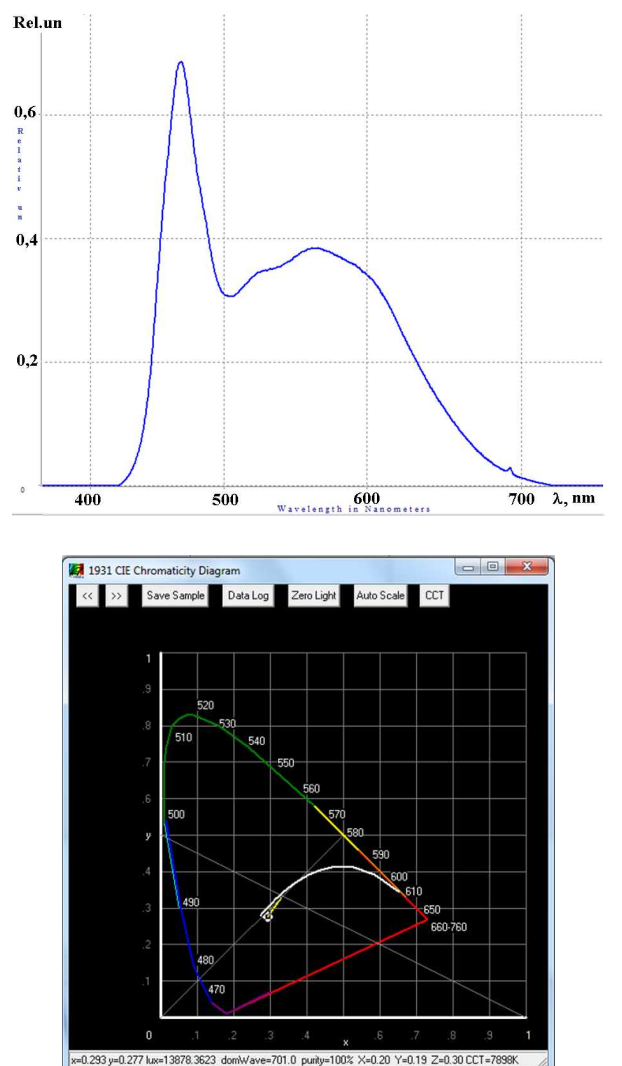

Fig. 5. Relative SPD of the lamp. The current's values: $\mathrm{I}_{\mathrm{CXA}}=400 \mathrm{~mA}, \mathrm{I}_{\mathrm{BLUE}}=450 \mathrm{~mA} . \mathrm{CCT} \approx 7900 \mathrm{~K}$.

The total luminous flux varies from $1500 \mathrm{~lm}$ to about $1600 \mathrm{~lm}$.

- $\mathrm{I}_{\mathrm{CXA}}=500 \mathrm{~mA}$; the current's value through blue LEDs is changed from $\mathrm{I}_{\mathrm{BLUE}}=200 \mathrm{~mA}$ up to $\mathrm{I}_{\mathrm{BLUE}}=800 \mathrm{~mA}$. CCT of the luminous flux changes from about $4500 \mathrm{~K}$ to about $9500 \mathrm{~K}-$ fig. 6.

The total luminous flux varies from $1700 \mathrm{~lm}$ to about $1900 \mathrm{~lm}$. 


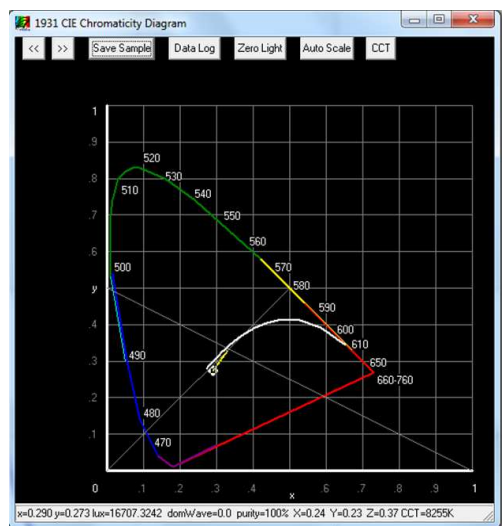

Fig. 6. Relative SPD of the lamp. The current's values: $\mathrm{I}_{\mathrm{CXA}}=500 \mathrm{~mA}, \mathrm{I}_{\mathrm{BLUE}}=600 \mathrm{~mA} . \mathrm{CCT} \approx 8200 \mathrm{~K}$.

- $\mathrm{I}_{\mathrm{CXA}}=600 \mathrm{~mA}$; the current's value through blue LEDs is changed from $\mathrm{I}_{\mathrm{BLUE}}=200 \mathrm{~mA}$ up to $\mathrm{I}_{\mathrm{BLUE}}=800 \mathrm{~mA}$. CCT of the luminous flux changes from about $4500 \mathrm{~K}$ to about $7900 \mathrm{~K}-$ fig. 7.

The total luminous flux varies from $1900 \mathrm{~lm}$ to about $2100 \mathrm{~lm}$.

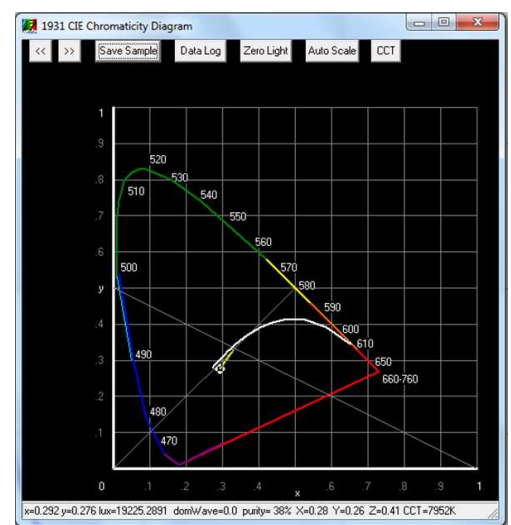

Fig. 7. Relative SPD of the lamp. The current's values: $\mathrm{I}_{\mathrm{CXA}}=600 \mathrm{~mA}, \mathrm{I}_{\mathrm{BLUE}}=800 \mathrm{~mA} . \mathrm{CCT} \approx 7900 \mathrm{~K}$.

- $\mathrm{I}_{\mathrm{CXA}}=700 \mathrm{~mA}$; the current's value through blue LEDs is changed from $\mathrm{I}_{\mathrm{BLUE}}=200 \mathrm{~mA}$ up to $\mathrm{I}_{\mathrm{BLUE}}=800 \mathrm{~mA}$. CCT of the luminous flux changes from about $4200 \mathrm{~K}$ to about $7000 \mathrm{~K}-$ fig. 8 .

The total luminous flux varies from $2200 \mathrm{~lm}$ to about $2400 \mathrm{~lm}$.

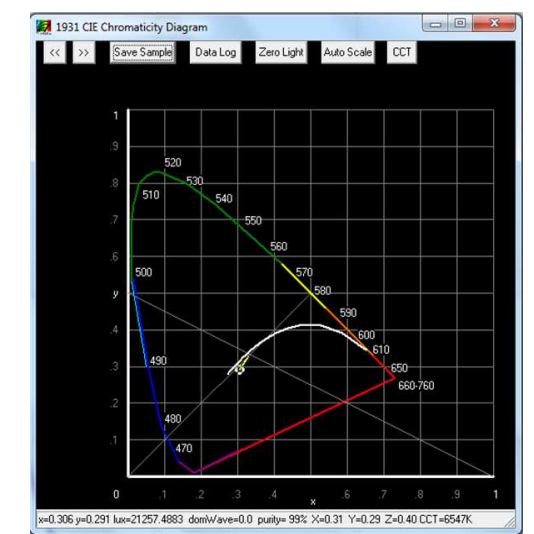

Fig. 8. Relative SPD of the lamp. The current's values: $\mathrm{I}_{\mathrm{CXA}}=700 \mathrm{~mA}, \mathrm{I}_{\mathrm{BLUE}}=600 \mathrm{~mA} . \mathrm{CCT} \approx 6500 \mathrm{~K}$.

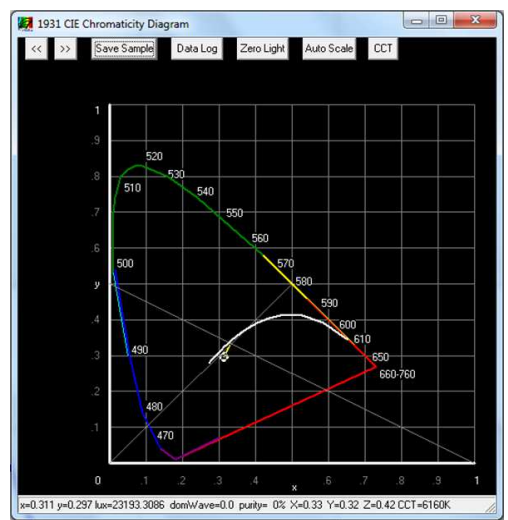

Fig. 9. Relative SPD of the lamp. The current's values: $\mathrm{I}_{\mathrm{CXA}}=800 \mathrm{~mA}, \mathrm{I}_{\mathrm{BLUE}}=600 \mathrm{~mA} . \mathrm{CCT} \approx 6150 \mathrm{~K}$.

- $\mathrm{I}_{\mathrm{CXA}}=800 \mathrm{~mA}$; the current's value through blue LEDs is changed from $\mathrm{I}_{\mathrm{BLUE}}=200 \mathrm{~mA}$ up to $\mathrm{I}_{\mathrm{BLUE}}=800 \mathrm{~mA}$. CCT of the luminous flux changes from about $4200 \mathrm{~K}$ to about $6500 \mathrm{~K}-$ fig. 9.

The total luminous flux varies from $2400 \mathrm{~lm}$ to about $2600 \mathrm{~lm}$.

So, it can be seen from figures $3 \div 9$, that as a larger part of the blue LEDs' radiant flux in total luminous flux, as its light is colder, i.e. the CCT is higher.

\section{Night lighting}

As it is noted above, the night lighting in hospitals, nursing homes and others should be in orange - red region not to interfere with sleep of the patients. At the same time there must be sufficient visibility for safe movement and to enable staff to perform their duties. Experimental investigations using red, red - orange and amber XPE LEDs Xlamp - CREE Inc. were carried out. Spectral power distribution (SPD) of combination of 6 red and 2 amber XPE LEDs is shown in fig. 10.

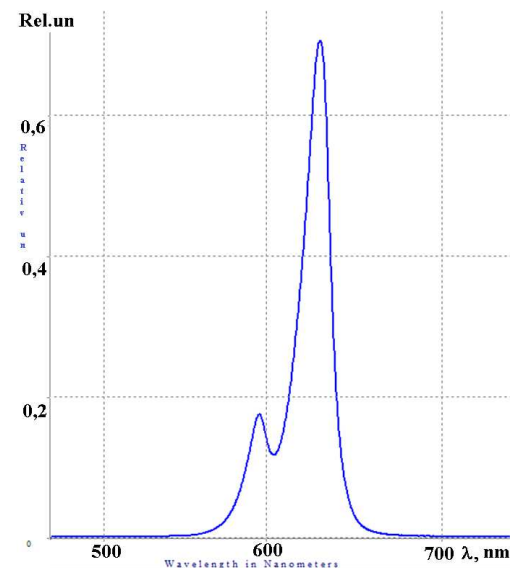

Fig. 10. Measured SPD of the 6 red and 2 amber XPE LEDs CREE Inc.; current is $350 \mathrm{~mA}$.

Despite the desire to expand the spectral characteristics of the luminous flux, finally we gave up using of amber LEDs as their light output strongly depends on the junction temperature - at $85^{\circ} \mathrm{C}$ it 
Environment. Technology. Resources, Rezekne, Latvia Proceedings of the $11^{\text {th }}$ International Scientific and Practical Conference. Volume III, 207-212

decreased to below $30 \%$ of the light output at $25^{\circ} \mathrm{C}$. The experimental lamp is realized using eight red XPE LEDs.

D. Junction temperatures and LEDs' thermal load experimental investigations

The LED module is tested in a thermal chamber. The ambient temperature is changed from $20^{\circ} \mathrm{C}$ to $40^{\circ} \mathrm{C}$. When it reaches desired value, the temperature is kept constant. The solder points and case temperatures are measured using IR camera Therma Cam E300 - FLIR Systems and verified by thermocouples - fig. 11 .

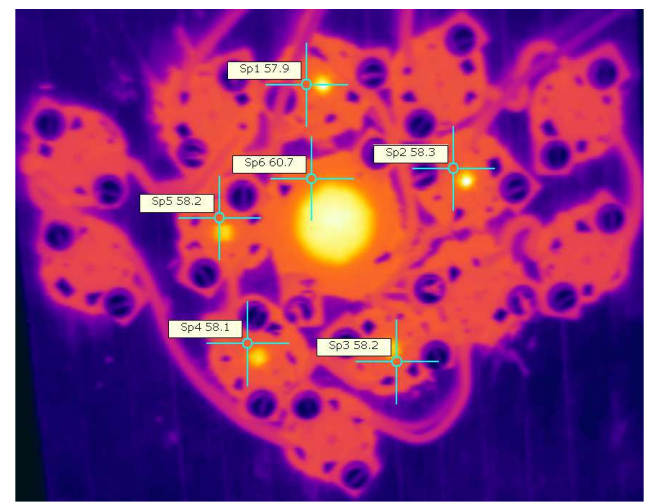

Fig. 11 Thermal load in daylight/noon LEDs regime. Ambient temperature is $\mathrm{T}_{\mathrm{a}}=40^{\circ} \mathrm{C}$. Blue LEDs solder points are around $\mathrm{T}_{\mathrm{sp}} \approx 58^{\circ} \mathrm{C}$. The CXA corpus temperature is $\mathrm{T}_{\mathrm{c}} \approx 61^{\circ} \mathrm{C}$.

The corresponding junction temperatures are then calculated using the equation:

$$
\mathrm{Tj}=\mathrm{Tsp}+(\mathrm{If} * \mathrm{Uf} * \mathrm{Rj}-\mathrm{sp})
$$

for the blue LEDs and equation:

$$
\mathrm{Tj}=\mathrm{Tc}+(\mathrm{If} * \mathrm{Uf} * \mathrm{Rj}-\mathrm{c})
$$

for the white module (CXA2520).

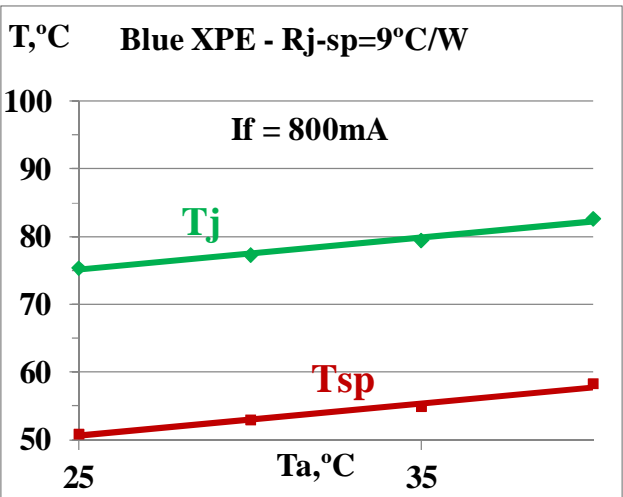

Fig. 12. Junction $(\mathrm{Tj})$ and solder point $(\mathrm{Tsp})$ temperatures in various ambient conditions: The temperature of the thermal chamber (Ta) is gradually increased.

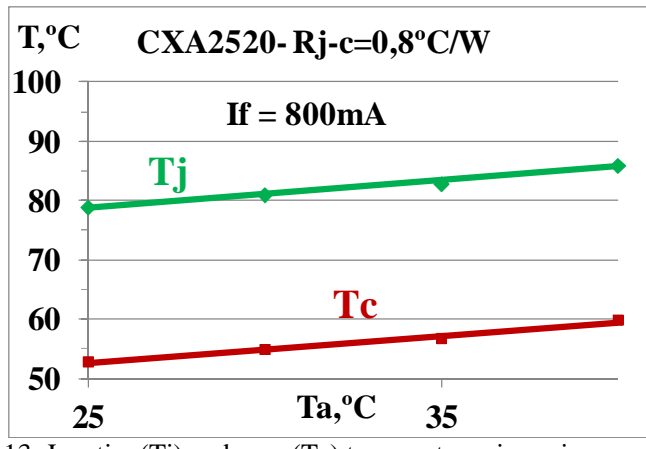

Fig. 13. Junction $(\mathrm{Tj})$ and case $(\mathrm{Tc})$ temperatures in various ambient conditions: The temperature of the thermal chamber (Ta) is gradually increased.

The worst LEDs' heat load is at daily mode of operation at maximum values of the currents through the white LED module and the blue LEDs. The experiments show that even then for all LEDs junction temperatures (figures 12, 13) do not exceed $90^{\circ} \mathrm{C}$ even at severe ambient conditions $\left(\mathrm{Ta}=40^{\circ} \mathrm{C}\right)$.

\section{CONCLUSIONS}

Appropriate combinations of LEDs and LED modules for luminaire with features suitable for the lighting of hospitals, nursing homes, hospices and others are made. During the day spectral power distribution (SPD) of this type luminaire can simulate natural day light that affects the natural circadian rhythm of humans. Depending on the type of the patients the maximum color temperature of the light flux can be limited to three grades - for children $(\mathrm{CCT} \leq 4000 \mathrm{~K})$, adults (CCT varies to 6000 $\div 6500 \mathrm{~K}$ ) and the elderly (CCT varies to 7500 $\div 8000 \mathrm{~K}$ ). At night when the patients sleep luminous flux can be in the orange - red spectral region and its intensity can be remotely controlled from 0 to $100 \%$ to enable patients to sleep and staff to fulfill their obligations.

Performed experimental studies make possible achieving the desired characteristics of light and appropriate LEDs' modes of operation.

Thermal management of the module shows stable LED operation even at tough ambient conditions.

\section{V.ACKNOWLEDGMENTS}

The National Science Fund, Ministry of Education and Science of Bulgaria, is gratefully acknowledged for the financial support of research project DFNI B02/2 2014

\section{REFERENCES}

[1] https://www.thepaleomom.com/regulating-circadian-rhythm/

[2] LED_color_mixing; http://www.cree.com

[3] Bellia L., A. Pedace, G. Barbato, Lighting in educational environments: An example of a complete analysis of the effects of daylight and electric light on occupants, Building and Environment, 68 (2013), pp. 50-65.

[4] Cajochen C., Alerting effects of light, Sleep Medicine Reviews (2007)11, pp.453-464.

[5] Chellappa L. S., R. Steiner, P. Blattner, P. Oelhafen, T.Gotz, C. Cajochen, Non-Visual Effects of Light on Melatonin, 
Alertness and Cognitive Performance: Can Blue-Enriched Light Keep Us Alert?, Blue-Enriched Light, Alertness and Performance, January 2011, Volume 6, Issue 1, e16429, pp.1-12.

[6] Edwards L. and P. Torcellini, A Literature Review of the Effects of Natural Light on Building Occupants, U.S. Department of Energy Laboratory, 2002, p.58.

[7] Ellis E. V., E. W. Gonzalez, D. A. Kratzer, D. L. McEachron, G. Yeutter, Auto-tuning Daylight with LEDs: Sustainable Lighting for Health and Wellbeing, ARCC 2013,
The Visibility of Research Sustainability: Visualization Sustainability and Performance, pp.465-473.

[8] Gabel V., M. Maire, C. F. Reichert, S. L. Chellappa, C. Schmidt, V. Hommes, A. U. Viola and C. Cajochen, Effects of Artificial Dawn and Morning Blue Light on Daytime Cognitive Performance, Well-being, Cortisol and Melatonin Levels, Chronobiology International, Informa Healthcare USA, Inc (2013), pp.1-10. 